\title{
Alterations in sheep peripheral blood mononuclear cell proliferation and cytokine release by polyunsaturated fatty acid supplementation in the diet under high ambient temperature
}

\author{
Maria Giovanna Ciliberti, ${ }^{*}$ Marzia Albenzio,, ${ }^{*}$ Giovanni Annicchiarico,† Agostino Sevi, ${ }^{*}$ Antonio Muscio, ${ }^{*}$ \\ and Mariangela Caroprese ${ }^{* 1}$ \\ *Department of the Sciences of Agriculture, Food and Environment, University of Foggia, Via Napoli, 25, 71122 Foggia, Italy \\ †CRA, Istituto Sperimentale per la Zootecnia, Segezia, 71122 Foggia, Italy
}

\section{ABSTRACT}

The aim of this study was to investigate the effects of polyunsaturated fatty acid (PUFA) supplementation from different sources in the diet of dairy sheep under high ambient temperatures on ex vivo lymphocyte proliferation and inflammatory responses. The experiment was carried out during summer: 32 Comisana ewes were divided into 4 groups of 8 . The FS group was supplemented with whole flaxseed, the AG group was supplemented with Ascophyllum nodosum, the FS+AG group was supplemented with a combination of flaxseed and $A$. nodosum. The fourth group (CON group) was a control and received a diet containing no supplement. The average maximum temperature was around $33^{\circ} \mathrm{C}$ during wk 2 and 3 , whereas the mean temperature never decreased below $26^{\circ} \mathrm{C}$. Following 15 $\mathrm{d}$ of treatment with respective diets, peripheral blood mononuclear cells (PBMC) from sheep who received a diet supplemented with $A$. nodosum had impaired cell proliferation responses and IL-6 production after mitogen stimulation compared with $\mathrm{PBMC}$ from $\mathrm{FS}+\mathrm{AG}$ sheep. In addition, PBMC from AG sheep displayed impaired cell proliferation compared with cells from the CON group. The FS+AG cells produced lower levels of IL-10 than CON cells, and higher IL-6 than AG and CON cells. Results demonstrated that the supplementation with PUFA from different sources in a sheep's diet can influence their immunological responses under high ambient temperatures depending on the composition of fatty acid supplementation. In particular, synergistic effects of different PUFA from flaxseed and A. nodosum, simultaneously administrated in the sheep diet, were observed on activation of inflammation response. Key words: cytokine, sheep, proliferation, polyunsaturated fatty acid, inflammation

Received May 6, 2014

Accepted November 5, 2014.

${ }^{1}$ Corresponding author: mariangela.caroprese@unifg.it

\section{INTRODUCTION}

Farmed animals are subject to different types of stressors caused by both management procedures and environmental conditions. Stress can affect the immune system by altering immunological and inflammatory processes. In sheep, both physiological stress connected to gestation and lambing, and psychological stress, caused by isolation, increased in vivo plasma secretion of pro-inflammatory cytokines, including IL-6 (Caroprese et al., 2006, 2010). During an immunological challenge the balance between pro-inflammatory and antiinflammatory cytokines is an important mechanism to regulate the ongoing pro-inflammatory processes and to avoid tissue damage resulting from excessive inflammation. Interleukin-10 is a well-known anti-inflammatory cytokine whose main role is to reduce the production of inflammatory mediators after immunological challenges (Murray, 2006). During the summer season in the Mediterranean basin, dairy animals are exposed to climatic conditions that often result in a depression of the immune system (Lacetera et al., 2005).

Interest is growing on the effects exerted by dietary fats on immune cell functions (Calder, 1996a,b, 1997, 1998). In dairy sheep and cows under heat stress, the dietary supplementation of whole flaxseed, rich in $\alpha$-linolenic acid (C18:3n-3, ALA), resulted in an enhancement of humoral and cell-mediated responses, and in an alteration of plasma IL-10 secretion (Caroprese et al., 2009, 2012). Ascophyllum nodosum is a macroalgae rich in polysaccharides, PUFA, eicosapentaenoic acid (C20:5n-3, EPA), and antioxidants (Devi et al., 2008). Recently, A. nodosum was administrated in the diet of dairy cows and sheep to verify the effects on their hematological parameters and immunological responses. An increase of blood glucose and a decrease in sorbitol dehydrogenase in dairy cows was found (Karatzia et al., 2012; Novoa-Garrido et al., 2014). To the best of our knowledge, no studies have evaluated the effects of supplementation of $A$. nodosum to dairy sheep during 
summer, and on the activation of their inflammatory responses in terms of cytokine secretion.

Knowing the effects of high ambient temperatures on the activation of inflammatory response and its alteration after dietary supplementation of PUFA from different sources could be crucial to understanding sheep immune reactivity during the summer season to reduce the susceptibility to infectious diseases. We hypothesized that the supplementation of PUFA from whole flaxseed or from the macroalgae $A$. nodosum to dairy sheep during the summer season might influence the ex vivo activation of inflammatory response, in terms of pro-inflammatory and anti-inflammatory cytokine secretion and lymphocyte proliferation. This study, therefore, was undertaken to evaluate the effects of PUFA supplementation, administrated as whole flaxseed, A. nodosum, and a combination of flaxseed and $A$. nodosum, in the diet of dairy sheep under high ambient temperatures on ex vivo lymphocyte proliferation and inflammatory responses.

\section{MATERIALS AND METHODS}

\section{Animals and Experimental Design}

The experiment was conducted during the summer (June-July) of 2012 at Segezia research station of the Council for Research and Experimentation in Agriculture (CRA-ZOE). In the experimental design, 4 balanced groups each with 4 Cominsana ewes (d 202.1 \pm 5.3 of lactation, mean $\pm \mathrm{SD}$ ) were assigned to 1 of 4 dietary treatments in a $2 \times 2$ factorial arrangement. Additionally, as a split-plot component, the blood samples taken from each ewe were treated differently ex vivo in the laboratory (see additional explanation below). The 4 dietary treatments were (1) control $(\mathbf{C O N})$ in which ewes received $1 \mathrm{~kg} /$ ewe per d of pelleted concentrate (Mangimificio Molino Gallo, Potenza, Italy); (2) supplemental whole flaxseed (FS; Lin Tech, Tecnozoo srl, Torreselle di Piombino Dese, Italy); (3) A. nodosum (AG; Tasco, Acadian Seaplants, Canada); or (4) the combination of FS and AG (FS+AG). The groups were balanced for milk yield $(273.5 \pm 7.9 \mathrm{~g} / \mathrm{d}$ for the CON group, $268.2 \pm 8.30 \mathrm{~g} / \mathrm{d}$ for the FS group, $269.4 \pm 9.41$ for the AG group, and $273 \pm 8.05$ for the $\mathrm{FS}+\mathrm{AG}$ group), BW $(55.4 \pm 1.2 \mathrm{~kg}$ for the CON group, $54.7 \pm 0.9 \mathrm{~kg}$ for the FS group, $55.5 \pm 1.1 \mathrm{~kg}$ for the AG group, and $55 \pm 1.1 \mathrm{~kg}$ for the FS+AG group), and BCS $(2.56 \pm 0.1$ for the CON group, $2.5 \pm 0.2$ for the FS group, $2.52 \pm 0.1$ for the AG group, and $2.53 \pm 0.1$ for the FS+AG group).

In the split-plot component of the experiment, an ex vivo study was performed involving isolations of sheep peripheral blood mononuclear cells (PBMC), and the evaluation of their proliferative response and cytokine production after stimulation with the mitogen phytohemagglutinin-(PHA) stimulated cells (SC), or not (NSC) was carried out. More details of sample collection and laboratory analysis are described subsequently.

Each animal received $1.8 \mathrm{~kg} /$ ewe per d of oat hay in 2 meals a day. Animal feeding procedures were described in Caroprese et al. (2014). In particular, ewes in the FS group received $750 \mathrm{~g}$ /ewe per d of pelleted concentrate, and $250 \mathrm{~g} /$ ewe per d of whole flaxseed; ewes in the AG group received $1 \mathrm{~kg} /$ ewe per d of pelleted concentrate in which $5 \%$ A. nodosum was incorporated; ewes in the FS+AG group were supplemented with both flaxseed $(250 \mathrm{~g} / \mathrm{d})$ and pelleted concentrate incorporating $5 \% \mathrm{~A}$. nodosum. Water was available ad libitum for all groups from automatic drinking troughs at any time of day.

During the trial, ambient temperature and relative humidity in indoor and outdoor areas were monitored with thermo-hygrographs (LSI, I-20090 Settala Premenugo-Milano, Italy) placed at $1.5 \mathrm{~m}$ from the floor. Data on maximum and mean ambient temperatures are reported in Figure 1.

All procedures were conducted according to the guidelines of the European Union Directive 2010/63/ EU (EU Directive, 2010) on the protection of animals used for experimental and other scientific purposes. The ewes were healthy and their conditions were carefully examined by veterinarians throughout the trial to exclude the presence of any signs of disease.

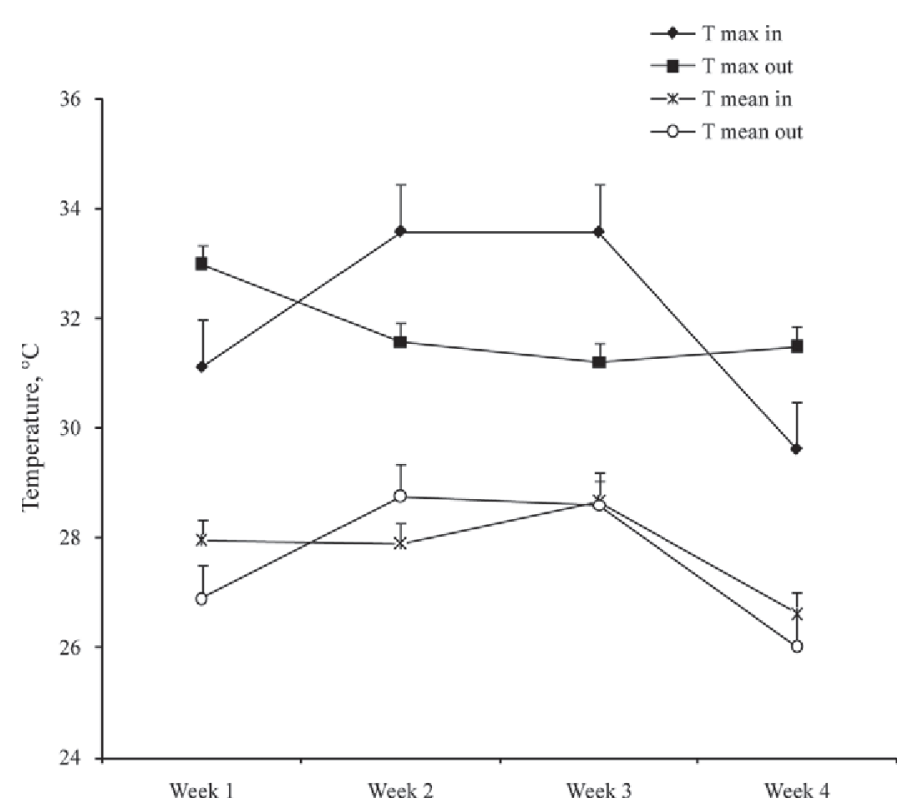

Figure 1. Means $\pm \mathrm{SE}$ of maximum (T max) and mean ambient temperature (T mean) measured detected inside (in) and outside (out) the experimental pens during the weeks of the experimental period. 
The chemical composition of diets was carried out by standard procedures (AOAC, 1990). The chemical composition of the diets was reported in Caroprese et al. (2014). Briefly, the control diet contained $12.53 \%$ $\mathrm{CP}, 1.93 \%$ ether extract, $53.36 \% \mathrm{NDF}$, and $1.30 \mathrm{Mcal} /$ $\mathrm{kg}$ of $\mathrm{NE}_{\mathrm{L}}$ (NRC, 2001); the FS diet contained $12.90 \%$ $\mathrm{CP}, 5.02 \%$ ether extract, $54.58 \% \mathrm{NDF}$, and $1.29 \mathrm{Mcal} /$ $\mathrm{kg}$ of $\mathrm{NE}_{\mathrm{L}}$; the $\mathrm{AG}$ diet contained $12.84 \% \mathrm{CP}, 2.04 \%$ ether extract, $53.32 \% \mathrm{NDF}$, and $1.31 \mathrm{Mcal} / \mathrm{kg}$ of $\mathrm{NE}_{\mathrm{L}}$; and the $\mathrm{AG}+\mathrm{FS}$ diet contained $13.20 \% \mathrm{CP}, 5.12 \%$ ether extract, $54.55 \% \mathrm{NDF}$, and $1.30 \mathrm{Mcal} / \mathrm{kg}$ of $\mathrm{NE}_{\mathrm{L}}$ (calculated on a DM basis).

The fatty acid composition of whole flaxseed and $A$. nodosum is reported in Table 1 . The determination of methyl esters of the diet ingredients was carried out according to O'Fallon et al. (2007). Briefly, $1 \mathrm{~g}$ of the sample was added into a screw-cap $(16 \times 25 \mathrm{~mm})$ reaction tube in which $1.0 \mathrm{~mL}$ of C13:0 (0.5 $\mathrm{mg}$ of C13:0/ $\mathrm{mL}$ of $\mathrm{MeOH}), 0.7 \mathrm{~mL}$ of $\mathrm{KOH}$ and $5.3 \mathrm{~mL}$ of $\mathrm{MeOH}$ was added. During incubation at $55^{\circ} \mathrm{C}$ for $1 \mathrm{~h}$ and 30 min, the tubes were inverted to mix for $5 \mathrm{~s}$ every 20 min. After cooling in a cold water bath, $3 \mathrm{~mL}$ of hexane were added into each tube and vortex for $5 \mathrm{~min}$. The tubes were centrifuged at room temperature for $5 \mathrm{~min}$ at $500 \mathrm{~g}$; supernatant $(1 \mathrm{~mL})$ was taken from each tube and transferred into vials and stored at $-20^{\circ} \mathrm{C}$ until GC analysis. Fatty acid profile was quantified using 6890N GC (Agilent Technologies, Santa Clara, CA), equipped with a flame ionization detector. Helium was the carrier gas and the gas flow rate was $175 \mathrm{kPa}$. The oven temperature was initially held at $70^{\circ} \mathrm{C}$ for $4 \mathrm{~min}$, and then programmed to $175^{\circ} \mathrm{C}$ at $13^{\circ} \mathrm{C} / \mathrm{min}$ increase and held isothermally for $45 \mathrm{~min}$. The column used was a capillary column (HP88; $100 \mathrm{~m} \times 0.24 \mathrm{~mm}$ i.d., 0.20 $\mu \mathrm{m}$ film thickness, Agilent Technologies). Concentrations of FAME were analyzed utilizing a calibration curve with a mixture of standards of 50 fatty acids (GLC Reference standard 674, Nu-Chek Prep Inc., Elysian, MN). The flaxseed fatty acid composition, as reported in Table 1, was mainly characterized by 53.21 $\mathrm{g} / 100 \mathrm{~g}$ of total FA of ALA, whereas A. nodosum was characterized by $37.03 \mathrm{~g} / 100 \mathrm{~g}$ of FA of C18:1 cis-9 and by $5.03 \mathrm{~g} / 100 \mathrm{~g}$ FA of EPA.

\section{Isolation of PBMC}

At $15 \mathrm{~d}$ of the experiment blood samples $(15 \mathrm{~mL})$ were collected in vacuum tubes from a jugular vein of the sheep. Isolation of PBMC was performed by density gradient centrifugation according to Wattegedera et al. (2004). Blood samples were collected into heparinized Vacutainer tubes which were diluted 1:5 in PBS $(\mathrm{pH}$ 7.4 , at $4^{\circ} \mathrm{C}$ ), and centrifuged at $670 \times \mathrm{g}$, at $4^{\circ} \mathrm{C}$ for 20 min. The buffy coat was recovered, layered over a Ficoll gradient $(1.077 \mathrm{~g} / \mathrm{mL})$, and centrifuged at $1,130 \times g$, $15^{\circ} \mathrm{C}$ for $30 \mathrm{~min}$. The mononuclear cell band was collected and washed 3 times by centrifugation at $240 \times g$, $4^{\circ} \mathrm{C}$ for $10 \mathrm{~min}$ in Hanks' buffered saline solution supplemented with $10 \mathrm{U} / \mathrm{mL}$ of heparin (Sigma-Aldrich, Milan, Italy), $50 \mu \mathrm{g} / \mathrm{mL}$ of gentamicin (Euroclone, Milan, Italy), and 2\% FBS (Biochrom, Berlin, Germany). The $\mathrm{PBMC}$ were finally resuspended at a final concentration of $2 \times 10^{6}$ cells $/ \mathrm{mL}$ in Iscove's modified Dulbecco's medium (Euroclone) supplemented with 10\% FBS and $50 \mu \mathrm{g} / \mathrm{mL}$ of gentamicin.

\section{PBMC for Lymphocyte Stimulation Assay and IL Determination}

Lymphocyte proliferation assays were performed adding $100 \mu \mathrm{L}$ of cell suspension into quadruplicate wells of 96 well U-bottom plates. The PBMC were activated with $50 \mu \mathrm{L}$ of PHA (Sigma-Aldrich) at a final concentration of $5 \mu \mathrm{g} / \mathrm{mL}$ (SC), or not (NSC), as previously described by Tsai et al. (2008). The plates were incubated at $37^{\circ} \mathrm{C}$ and $5 \% \mathrm{CO}_{2}$ in a humidified incubator for $96 \mathrm{~h}$. After $96 \mathrm{~h}$ of incubation, cell suspensions were centrifuged at $300 \times \mathrm{g}, 4^{\circ} \mathrm{C}$ for $10 \mathrm{~min}$, and cell-free supernatants from each well were collected and stored at $-20^{\circ} \mathrm{C}$ until ELISA to measure cytokine production. After cellfree supernatant collection, cells were incubated with bromodeoxyuridine (Exalpha Biologicals Inc., Shirley, MA), to test lymphocyte proliferation. After $18 \mathrm{~h}$ of incubation, bromodeoxyuridine incorporation during DNA synthesis was measured by determining optical density with a titer-ELISA spectrophotometer (Power Wave XS, Biotek, Potton, UK) at $450 \mathrm{~nm}$.

\section{Determination of IL in Culture Supernatant by ELISA Test}

The levels of IL-6 in cell-free supernatants were determined by capture ELISA performed on 96-well microtiter plates, according to Caroprese et al. (2006)

Table 1. Fatty acid composition of diet flaxseed and Ascophyllum nodosum supplemented in the sheep diet

\begin{tabular}{lcc}
\hline $\begin{array}{l}\text { FA, } \mathrm{g} / 100 \mathrm{~g} \\
\text { of total FA }\end{array}$ & Flaxseed & A. nodosum \\
\hline C14:0 & & \\
C16:0 & 5.53 & 12.80 \\
C16:1 cis & 0.08 & 1.27 \\
C18:0 0 & 3.56 & 0.82 \\
C18:1 cis-9 & 16.29 & 37.03 \\
C18:2 cis-9, cis-12 & 16.75 & 9.33 \\
C18:3n-3 & 53.21 & 5.82 \\
C20:5n-3 & 0.01 & 5.03 \\
C22:5n-3 & 0.01 & 0.02 \\
\hline
\end{tabular}


with some modifications. Mouse monoclonal antibodies (mAb) specific for ovine IL-6 (Clone 4B6, Serotec Ltd., Killington, UK; $100 \mu \mathrm{L}$, at final concentration of $2 \mu \mathrm{g} /$ $\mathrm{mL}$ ) dissolved in PBS ( $\mathrm{pH} 7.2$ ) were used to coat wells and were incubated overnight at $4^{\circ} \mathrm{C}$. After washing with PBS (pH 7.2) and $0.05 \%$ Tween 20 (PBST), the plates were incubated with $200 \mu \mathrm{L} /$ well of $10 \%$ reconstituted commercial bovine skim milk at $37^{\circ} \mathrm{C}$ for $1 \mathrm{~h}$ to block nonspecific binding. Plates were then washed 4 times with PBST and the supernatants $(100 \mu \mathrm{L}$ per well) were added and incubated for $1 \mathrm{~h}$. The PBST provided negative control wells. Plates were then washed 4 times with PBST. Rabbit polyclonal anti-ovine IL-6 antibody (Serotec Ltd., UK), were used as detecting antibodies $(0.005 \mathrm{mg} / \mathrm{mL}$ diluted in $1 \%$ BSA in PBST) to determine captured IL-6 and were incubated at $37^{\circ} \mathrm{C}$ for $1 \mathrm{~h}$. The presence of bindings for IL-6 was detected using sheep anti-rabbit IgG conjugated to horseradish peroxidase (HRP, Sigma Aldrich, Milan, Italy). Optical density was measured at a wavelength of $450 \mathrm{~nm}$. Culture supernatants were read against a standard curve obtained using scalar dilution of recombinant ovine IL-6 (Kingfisher Biotech Inc., St Paul, MN). Data were expressed as nanograms per milliliter of IL-6.

Interferon- $\gamma$ and IL-10 in plasma were assayed by an ELISA test as briefly described in the following: 96-well plates (Sterilin, Newport, UK) were coated overnight at $4^{\circ} \mathrm{C}$ with $100 \mu \mathrm{L}$ of anti-bovine IFN- $\gamma$ and IL-10 mAb (Clone CC330 for IFN- $\gamma$ and Clone CC318 for IL-10, Serotec) in PBS $(2 \mu \mathrm{g} / \mathrm{mL})$. After washing with PBST, the antibody was blocked with PBS/1\% BSA for $1 \mathrm{~h}$. The IFN- $\gamma$ and IL-10 standard and samples were added to plate for $1 \mathrm{~h}$ at room temperature after washing 4 times. Biotinylated secondary anti-bovine IFN- $\gamma$ and IL-10 mAb (Clone CC302 for IFN- $\gamma$ and Clone CC320 for IL-10, Serotec) in PBS $(0.5 \mu \mathrm{g} / \mathrm{mL})$ were added for $1 \mathrm{~h}$ followed by $100 \mu \mathrm{L}$ of streptavidin-HRP $(2 \mu \mathrm{g} / \mathrm{mL}$ in PBS, Serotec). After washing, $100 \mu \mathrm{L}$ of $3,3^{\prime}, 5,5^{\prime}$-tetramethylbenzidine substrate solution was added to each well for $30 \mathrm{~min}$; to stop the reaction, 50 $\mu \mathrm{L}$ of $\mathrm{H}_{2} \mathrm{SO}_{4}(4 M)$ was added to each well. The levels of IFN- $\gamma$ and IL-10 were measured colorimetrically at $450 \mathrm{~nm}$ (by subtracting absorbance at $540 \mathrm{~nm}$ ) and quantified by interpolation from standard curve. Data were expressed as picograms per milliliter of IFN- $\gamma$ and as nanograms per milliliter of IL-10.

\section{Statistical Analysis}

All variables were tested for normality using the Shapiro-Wilk test (Shapiro and Wilk, 1965). All the data were analyzed using ANOVA for mixed models using the MIXED procedure of SAS Institute Inc. (2013), having the diet, the PHA stimulation and their interac- tions as fixed effects, and the animal as a random factor nested in the treatment. The model used was

$$
\mathrm{y}_{\mathrm{ijk}}=\mu+\mathrm{D}_{\mathrm{i}}+\mathrm{S}_{\mathrm{j}}+\delta_{\mathrm{ik}}+(\mathrm{DS})_{\mathrm{ij}}+\varepsilon_{\mathrm{ijk}},
$$

where $\mu=$ the overall mean, $\mathrm{D}=$ the effect of level $\mathrm{i}$ of factor diet, $\mathrm{S}=$ the effect of level $\mathrm{j}$ of factor stimulation, $\delta=$ the main plot error within diet, DS $=$ diet $\times$ stimulation, and $\varepsilon=$ the split-plot error.

When significant effects were found $(P<0.05)$, the Fisher's least significant difference test was used to locate significant differences between means.

\section{RESULTS}

\section{Proliferative Response to PHA}

Dietary treatment had a significant effect $(P<0.05)$ on proliferation of PBMC; on average, proliferation of PBMC was lower in mononuclear cells collected from sheep fed AG than in sheep fed FS+AG and the CON diet (Figure 2). The PBMC from the FS diet displayed an intermediate proliferation. An effect of stimulation was found $(P<0.05)$; proliferation of PBMC in presence of PHA increased compared with proliferation of PBMC with no stimulation.

\section{Cytokines Production by PBMC}

A significant interaction between the diet and the stimulation with PHA was found for IL-10 production $(P<0.05$, Figure 3$)$; in CON, AG, and FS supernatants from PBMC stimulated with PHA, the levels of IL-10 were higher than in CON, AG, and FS supernatants from PBMC without stimulation. In supernatants from PBMC stimulated with PHA and collected from

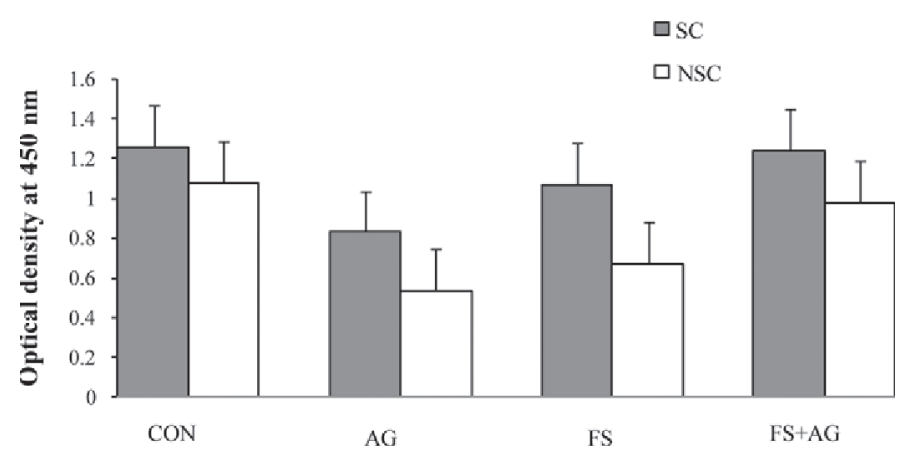

Figure 2. Proliferation of sheep peripheral blood mononuclear cells (PBMC) phytohemagglutinin (PHA)-stimulated (SC) or not (NSC; least squares means $\pm \mathrm{SEM}$ ). The PBMC were isolated from sheep fed the control diet $(\mathrm{CON})$ or supplemented with Ascophyllum nodosum (AG), flaxseed (FS), or a combination of $A$. nodosum and flaxseed $($ AG+FS). Diet, $P<0.05$; PHA, $P<0.05$. 


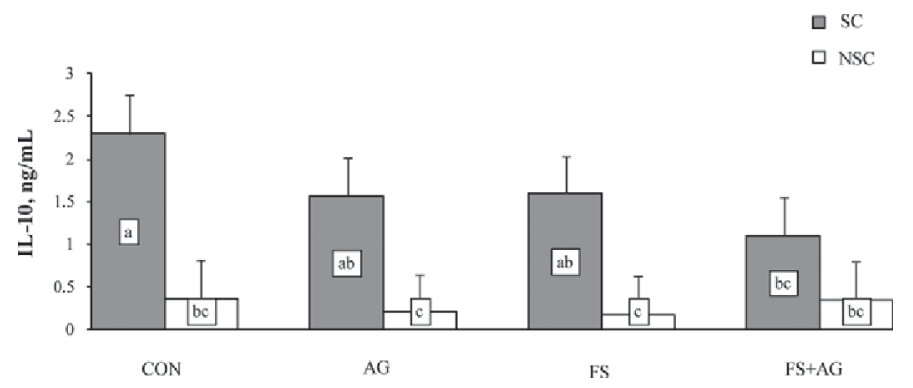

Figure 3. Interleukin-10 production (least squares means $\pm \mathrm{SEM}$ ), in phytohemagglutinin (PHA)-stimulated (SC) or not (NSC) peripheral blood mononuclear cells (PBMC) isolated from sheep fed control diet (CON) or supplemented with Ascophyllum nodosum (AG), flaxseed (FS), or a combination of $A$. nodosum and flaxseed (AG+FS). Different letters show significant differences $(P<0.05)$. Diet $\times$ PHA, $P<0.05 ;$ PHA, $P<0.05$.

FS+AG sheep, the levels of IL-10 were lower than in supernatants from PBMC collected from CON sheep stimulated with PHA $(P<0.05)$.

The diet did not affect IFN- $\gamma$ production, whereas a significant effect of the stimulation with PHA $(P<$ 0.001) emerged. The PBMC collected from AG, FS, and FS+AG stimulated with PHA secreted a higher concentration of IFN- $\gamma$ than nonstimulated PBMC $(P$ $<0.05$; Figure 4).

Ex vivo production of IL- 6 was affected by diet $(P<$ $0.05)$; data showed that on average the production of IL-6 was higher in supernatants from PBMC collected from FS+AG sheep than in supernatants from PBMC collected from AG and CON sheep. Moreover, the production of IL-6 was lower when PBMC were stimulated with PHA $(P<0.01)$.

The FS+AG nonstimulated cells produced higher levels of IL-6 than both CON and AG nonstimulated cells $(P<0.01$ and $P<0.05$, respectively, Figure 5$)$. In

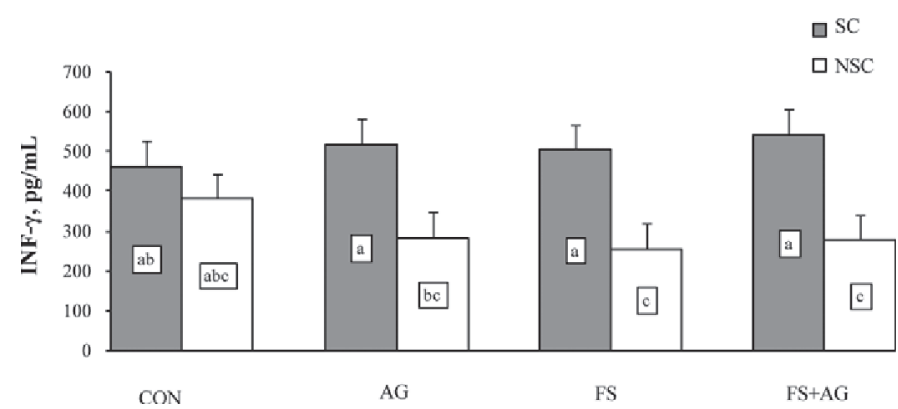

Figure 4. Interferon- $\gamma$ production (least squares means $\pm \mathrm{SEM}$ ), in phytohemagglutinin (PHA)-stimulated (SC) or not (NSC) peripheral blood mononuclear cells (PBMC) isolated from sheep fed the control diet (CON) or supplemented with Ascophyllum nodosum (AG), flaxseed (FS), or a combination of A. nodosum and flaxseed (AG+FS). Different letters show significant differences $(P<0.05)$. PHA, $P<$ 0.001 .

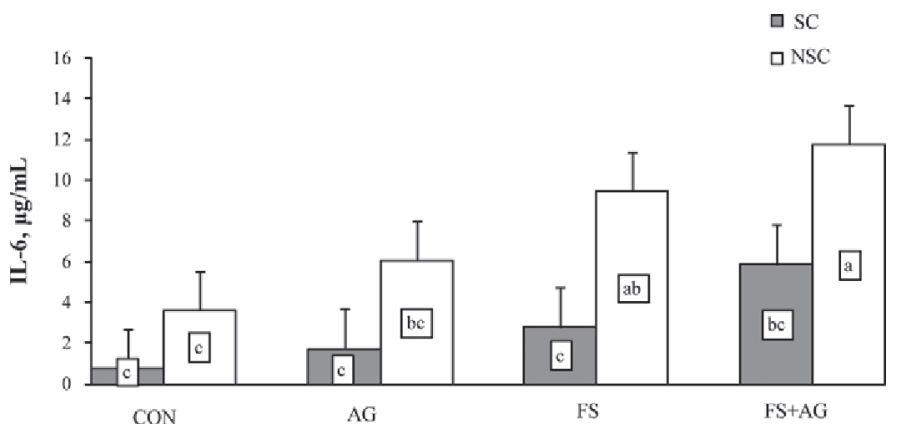

Figure 5. Interleukin-6 production (least squares means $\pm \mathrm{SEM}$ ) in phytohemagglutinin (PHA)-stimulated (SC) or not (NSC) peripheral blood mononuclear cells (PBMC) isolated from sheep fed control diet (CON) or supplemented with Ascophyllum nodosum (AG), flaxseed (FS), or a combination of A. nodosum and flaxseed (AG+FS). Different letters show significant differences $(P<0.05)$. Diet, $P<$ 0.05 ; PHA, $P<0.01$; diet $\times$ PHA, $P<0.05$.

addition, in FS and FS+AG supernatants a significant difference in IL-6 production was observed, with IL-6 increasing in supernatants from nonstimulated PBMC compared with PHA-stimulated PBMC $(P<0.05)$.

\section{DISCUSSION}

The main objective of this research was to analyze the effects of the supplementation of PUFA from different sources in the diet of sheep on activation of inflammatory response and its alterations under high ambient temperatures. Our hypothesis was that the introduction of PUFA from different sources in the diet of dairy sheep during the summer season might influence the ex vivo activation of inflammatory response. Nutritional adjustment of the diet and provision of supplements to lactating animals have a direct effect on physiological and immune functions (Caroprese et al., 2009, 2012), and ex vivo cell culture models can contribute to further investigate inflammation research.

Phytohemagglutinin is one of the most potent $\mathrm{T}$ cell mitogens and it stimulates $\mathrm{T}$ cells in a manner that promotes their long-term growth (Geppert, 1998). Our results confirmed that PHA stimulation enhanced the proliferation of sheep PBMC, regardless of the diet.

Several studies evaluated the possible effects of $A$. nodosum utilization in animal diet to improve the oxidative state and immune functions during stressful situations (Saker et al., 2004; Archer et al., 2007; Novoa-Garrido et al., 2014). However, a direct effect of A. nodosum dietary supplementation on PBMC proliferation in sheep was not investigated. In a previous study, extracts from a microalgae, Dunaliella tertiolecta, showed a suppressive effect on sheep PBMC proliferation in vitro (Caroprese et al., 2012). In addition, in the current experiment, a suppressive effect 
on PBMC collected from sheep supplemented with $A$. nodosum was observed. Previous studies reported that EPA can reduce proliferation in cell cultures (Calder, 2002). As a result, we could attribute the observed reduction in PBMC proliferation to the high EPA content of $A$. nodosum. The influence of n-3 PUFA dietary supplementation on the immune system of livestock could be related to the alteration of absorption of other nutrients relevant to the immune status, or to a direct effect of n-3 PUFA on the immune system (Wistuba et al., 2005). However, in a previous study on cows, ALA had no effects on lymphocyte proliferation in vitro (Thanasak et al., 2005). The supplementation of sheep under heat stress with whole flaxseed, rich in ALA, did not result in an enhancement of cell-mediated immune responses (Caroprese et al., 2012). Accordingly, ex vivo stimulation of PBMC proliferation in the present experiment was not affected by flaxseed supplementation in the sheep diet. In vitro and animal feeding studies, it was found that sufficient amounts of ALA can partially inhibit lymphocyte proliferation (Calder, 2002). When sheep were fed the combination of PUFA from A. nodosum and flaxseed, their lymphocyte proliferation increased compared with proliferation of PBMC from sheep fed $A$. nodosum alone. This result could be ascribed to the simultaneous action exerted on the immune system by PUFA from algae and flaxseed, namely EPA and ALA, supplemented in the diet of sheep. It has been stated in several animal and human studies that $\mathrm{n}-3$ fatty acids have different immunomodulatory activities, and among them, EPA is more biologically potent than ALA (Calder et al., 2002).

Interferon- $\gamma$ has pleiotropic effects by coordinating the link between immunological challenges, recognized by innate immune cells and the activation of acquired immunity, mainly in terms of cell-mediated immunity, and seems to be related to viral and parasitic infections (Coltman et al., 2001; Shtrichman and Samuel, 2001; Schroder et al., 2004). The IFN- $\gamma$ gene is a pivot in the growth of $\mathrm{T}$ lymphocytes induced by antigens (Tsai et al., 2008) and is an upregulator of the expression of chemokines (Boehm et al., 1997). Data from our experiment showed that the dietary supplementation of PUFA from flaxseed and $A$. nodosum did not exert an effect on the production of IFN- $\gamma$. This finding is in agreement with Wattegedera et al. (2004) who found that mitogen-activated ovine PBMC had no correlation between proliferation in response to mitogen and IFN- $\gamma$ production.

In sheep, the regulation of proliferation and INF- $\gamma$ production of ovine PBMC is profoundly linked to IL-10 production (Wattegedera et al., 2004). In cows fed flaxseed under heat stress, Caroprese et al. (2009) showed a decrease of IL-10 production in vivo, which supported immune responses during heat stress leading to the activation of cell-mediated immunity. Our present results, accordingly, showed a decrease of IL10 production by PBMC from sheep fed FS+AG and activated with PHA compared with IL-10 production in PBMC from CON sheep. The absence of decreased IL-10 production by PBMC from FS sheep compared with PBMC from CON sheep could be attributed to the increase in cortisol secretion observed in FS sheep (Caroprese et al., 2014). It is well known that glucocorticoids have a direct effect on IL-10 production because they are able to upregulate the IL-10 secretion by T cells (Elenkov and Chrousos, 1999). Data on the decrease of the production of IL-10 in sheep fed with PUFA from flaxseed and $A$. nodosum demonstrated the possible synergistic positive effect of the EPA, from $A$. nodosum, and ALA, from flaxseed, to limit the production of an anti-inflammatory mediator. The reduced release of IL-10, which is an important anti-inflammatory cytokine, promoted an ex vivo pro-inflammatory profile in FS+AG sheep.

Stress activates a HPA axis to synthesize cortisol, which controls the actions and the production of pro-inflammatory cytokines, such as IL-6 and TNF- $\alpha$ (Black, 2002; Caroprese et al., 2006). In our experiment, a synergistic reinforcing interaction between PUFA from flaxseed and $A$. nodosum was observed in the increase of IL-6 secretion by PBMC from FS+AG sheep compared with $\mathrm{CON}$ and AG sheep. The increase of expression of pro-inflammatory cytokines after acute physiological stress is useful to predict the ongoing of stress, both in animals and humans (Black, 2002). Indeed, in multiple lambing, sheep with high levels of IL-6 in vivo were found, this being a result of the activation of the immune system to cope with the physiological stress connected to multiple pregnancy (Caroprese et al., 2006). The interaction between stress and inflammation is a well-known biological mechanism that offers an animal engaged in a stressful situation, a survival advantage because an inflammatory response would help deal with any infectious organisms introduced during acting stress (Black, 2002). The increase in IL-6 production by $\mathrm{PBMC}$ from $\mathrm{FS}+\mathrm{AG}$ sheep can also be related to the concomitant reduction of IL-10 secretion by PBMC from FS+AG. The PBMC from sheep under high ambient temperatures and supplemented with PUFA from flaxseed and flaxseed in a combination of A. nodosum, showed a reduction in the IL-6 levels, when activated by PHA. In human PBMC activated by mitogens, the dietary inclusion of PUFA from flaxseed and fish oil caused a reduction of in vitro secretion of IL- 6 and TNF- $\alpha$ (Kelley, 2001). Several studies (Kelley et al., 1993, Caughey et al., 1996) reported that large amounts of ALA intake inhibited in vivo and ex vivo indices 
of immune response. The increase in IL- 6 production by $\mathrm{PBMC}$ from $\mathrm{FS}+\mathrm{AG}$ could be of some importance when considering that IL-6 is implicated in the development of acute septic shock following coliform mastitis, and can be considered the proinflammatory cytokine mainly evocated in Escherichia coli mastitis (Shuster et al., 1993; Riollet, 2000). Based on the influence exerted by the addition of flaxseed in combination with $A$. nodosum in the diet on sheep IL-6 production, it may be argued that the diet influenced innate immunity ex vivo. In contrast, the absence of results from the different diets on IFN- $\gamma$ production suggested that diets failed in affecting the transition from innate immunity to adaptive immunity, which is coordinated by IFN- $\gamma$, at least up to $15 \mathrm{~d}$.

Previous studies on the effects of $A$. nodosum on immune functions of ruminants did not consider the possibility of a connection between $A$. nodosum and cytokine production. This study is the first attempt to investigate this relation, to better explain the effect of $A$. nodosum on immune regulation found by other research groups (Saker et al., 2004; Novoa-Garrido et al., 2014).

\section{CONCLUSIONS}

This study demonstrated that the supplementation of PUFA from $A$. nodosum in the diet of sheep under high ambient temperatures influenced sheep immune responses with the reduction of lymphocyte proliferation. The combined supplementation of PUFA from flaxseed and $A$. nodosum, based on the presence of both ALA and EPA, showed a pro-inflammatory response as demonstrated by the increase in IL- 6 and the decrease in IL-10 productions. Results of the experiment demonstrated that the supplementation with PUFA from different sources in sheep can influence their immunological responses under high ambient temperatures in relation to the composition of fatty acid supplementation. Further studies are needed to evaluate the effects of PUFA from different sources on sheep cytokine profile under different types of stressors.

\section{ACKNOWLEDGMENTS}

The authors thank Claire Moore (University of Foggia, Foggia, Italy) for English revision.

\section{REFERENCES}

AOAC. 1990. Official Methods of Analysis. 15th ed. Association of Official Analytical Chemists, Arlington, VA.

Archer, G. S., T. H. Friend, D. Caldwell, K. Ameiss, and P. D. Krawczel. 2007. Effect of seeweed Ascophyllum nodosum on lambs during forced walking and transport. J. Anim. Sci. 85:225-232.
Black, P. H. 2002. Stress and inflammatory response: A review of neurogenic inflammation. Brain Behav. Immun. 16:622-653.

Boehm, U., T. Klamp, M. Grool, and J. C. Howard. 1997. Cellular responses to interferon-gamma. Annu. Rev. Immunol. 15:749-795.

Calder, P. C. 1996a. Effects of fatty acids and dietary lipids on cells of immune system. Proc. Nutr. Soc. 55:127-150.

Calder, P. C. 1996b. Immunomodulatory and anti-inflammatory effects of n-3 polyunsaturated fatty acids. Proc. Nutr. Soc. 55:737-774.

Calder, P. C. 1997. N-3 polyunsaturated fatty acids and cytokine production in health and disease. Ann. Nutr. Metab. 41:203-234.

Calder, P. C. 1998. Dietary fatty acids and the immune systems. Nutr. Rev. 56:S70-S83.

Calder, P. C. 2002. Dietary modification of inflammation with lipids. Proc. Nutr. Soc. 61:345-358.

Calder, P. C., P. Yaqoob, F. A. Thies Wallace, and E. A. Miles. 2002 Fatty acids and lymphocyte function. Br. J. Nutr. 87:S31-S48.

Caroprese, M., M. Albenzio, G. Annicchiarico, and A. Sevi. 2006. Changes occurring in immune responsiveness of single- and twinbearing Comisana ewes during the transition period. J. Dairy Sci. 89:562-568.

Caroprese, M., M. Albenzio, M. G. Ciliberti, M. Francavilla, and A. Sevi. 2012. A mixture of phytosterols from Dunaliella tertiolecta affects proliferation of peripheral blood mononuclear cells and cytokine production in sheep. Vet. Immunol. Immunopathol. 150:27-35.

Caroprese, M., M. Albenzio, A. Marzano, L. Schena, G. Annicchiarico, and A. Sevi. 2010. Relationship between cortisol response to stress and behavior, immune profile, and production performance of dairy ewes. J. Dairy Sci. 93:2395-2403.

Caroprese, M., M. G. Ciliberti, G. Annicchiarico, M. Albenzio, A. Muscio, and A. Sevi. 2014. Hypothalamic-pituitary-adrenal axis activation and immune regulation in heat-stressed sheep after supplementation with polyunsaturated fatty acids. J. Dairy Sci. 97:4247-4258

Caroprese, M., A. Marzano, G. Entrican, S. Wattegedera, M. Albenzio, and A. Sevi. 2009. Immune response of cows fed polyunsaturated fatty acids under high ambient temperatures. J. Dairy Sci. 92:2796-2803.

Caughey, G. E., E. Montzioris, R. A. Gibson, L. G. Cleland, and M. J. James. 1996. The effect on human tumor necrosis factor $\alpha$ and interleukin $1 \beta$ production of diets enriched in n-3 fatty acids from vegetable oil from fish oil. Am. J. Clin. Nutr. 63:116-122.

Coltman, D. W., K. Wilson, J. G. Pilkington, M. J. Stear, and J. M. Pemberton. 2001. A microsatellite polymorphism in the gamma interferon gene is associated with resistance to gastrointestinal nematodes in a naturally-parasitized population of Soay sheep. Parasitology 122:571-582.

Devi, K. P., N. Suganthy, P. Kesika, and S. K. Pandian. 2008. Bioprotective properties of seaweeds: In vitro evaluation of antioxidant activity and antimicrobial activity against food borne bacteria in relation to polyphenolic content. BMC Complement. Altern. Med. $8: 38$.

Elenkov, I. J., and G. P. Chrousos. 1999. Stress hormones, Th1/Th2 patterns, pro/anti-inflammatory cytokines and susceptibility to disease. Trends Endocrinol. Metab. 10:359-368.

EU Directive. 2010. 2010/63/EU of 22 September 2010 on the protection of animals used for scientific purposes, pp. 33-79. Official Journal L 276, European Communities Publication office, Luxembourg.

Geppert, T. 1998. Phytohemagglutinin (PHA). Encyclopedia of Immunology, Elsevier, 6:1952-1953.

Karatzia, M., E. Christaki, E. Bonos, C. Karatzias, and P. FlorouPaneri. 2012. The influence of dietary Ascophyllum nodosum on haematologic parameters of dairy cows. Ital. J. Anim. Sci. 11e31:169-173.

Kelley, D. S. 2001. Modulation of human immune and inflammatory responses by dietary fatty acids. Nutrition 17:669-673.

Kelley, D. S., G. J. Nelson, J. E. Love, L. B. Branch, P. C. Taylor, P. C. Schmidt, B. E. Mackey, and J. M. Iacono. 1993. Dietary a linolenic acid alters fatty acid composition, but not blood lipids, lipoproteins or coagulation status in humans. Lipids 28:533-537. 
Lacetera, N., U. Bernabucci, D. Scalia, B. Ronchi, G. Kuzminsky, and A. Nardone. 2005. Lymphocyte functions in dairy cows in hot environment. Int. J. Biometeorol. 50:105-110.

Murray, P. J. 2006. Understanding and exploiting the endogenous interleukin-10/STAT3-mediated anti-inflammatory response. Curr. Opin. Pharmacol. 6:379-386.

Novoa-Garrido, M., L. Aanesen, V. Lind, H. J. S. Larsen, and S. K. Jensen. 2014. Immunologial effects of feeding macroalgae and various vitamin E supplements in Norwegian white sheep-ewes and their offspring. Livest. Sci. 167:126-136. http://dx.doi. org/10.1016/j.livsci.2014.05.021.

NRC. 2001. Nutrient Requirements of Dairy Cattle. 7th rev. ed. Natl. Acad. Sci., Washington, DC.

O'Fallon, J. V., J. R. Busboom, M. L. Nelson, and C. T. Gaskins. 2007. A direct method for fatty acid methyl ester synthesis: Application to wet meat tissues, oils, and feedstuffs. J. Anim. Sci. 85:1511-1521.

Riollet, C.. P. Rainard, and B. Poutrel. 2000. Cells and cytokines in inflammatory secretions of bovine mammary gland. Adv. Exp. Med. Biol. 480:247-258

Saker, K. E., J. H. Fike, H. Veit, and D. L. Hard. 2004. Brown seaweed-(Tasco) treated conserved forage enhances antioxidant status and immune function in heat-stressed weather lambs. J. Anim. Physiol. Anim. Nutr. (Berl.) 88:122-130.

SAS Institute Inc. 2013. SAS Enterprise Guide: Statistics. Version 6.1 ed. SAS Inst. Inc., Cary, NC.

Schroder, K., P. J. Hertzog, T. Ravasi, and D. A. Hume. 2004. Interferon- $\gamma$ : An overview of signals, mechanisms and functions. J. Leukoc. Biol. 75:163-189.
Shapiro, S. S., and M. B. Wilk. 1965. An analysis of variance test for normality. Biometrika 52:591-601.

Shtrichman, R., and C. E. Samuel. 2001. The role of gamma interferon in antimicrobial immunity. Curr. Opin. Microbiol. 4:251-259.

Shuster, D. E., M. Kehrli, and M. G. Stervens. 1993. Cytokine production during endotoxin-induced mastitis in lactating dairy cows. Am. J. Vet. Res. 54:80-85.

Thanasak, J., K. E. Muller, S. J. Dieleman, A. Hoek, J. P. Noordhuizen, and V. P. Rutten. 2005. Effects of polyunsaturated fatty acids on the proliferation of mitogen stimulated bovine peripheral blood mononuclear cells. Vet. Immunol. Immunopathol. 104:289-295.

Tsai, W. J., Y. C. Chen, M. H. Wu, L. C. Lin, K. A. Chuang, S. C. Chang, and Y. C. Kuo. 2008. Seselin from Plumbago zeylanica inhibits phytohemoagglutinin (PHA)-stimulated cell proliferation in human peripheral blood mononuclear cells. J. Ethnopharmacol. 119:67-73.

Wattegedera, S., K. Sills, C. J. Howard, J. C. Hope, C. J. McInnes, and G. Entrican. 2004. Variability in cytokine production and cell proliferation by mitogen-activate ovine peripheral blood mononuclear cells: Modulation by interleukin (IL)-10 and IL-12. Vet. Immunol. Immunopathol. 102:67-76.

Wistuba, T. J., E. B. Kegley, J. K. Apple, and M. E. Davis. 2005. Influence of fish oil supplementation on growth and immune system characteristics of cattle. J. Anim. Sci. 83:1097-1101. 